\title{
Prediction of Hypertensive Disorders of Pregnancy by Measuring Cardiac Output in Early Pregnancy
}

\author{
Shakuntala Chhabra, Arpita Jaiswal and Anupriya Singh \\ Obstetrics Gynaecology, Mahatma Gandhi Institute of Medical Sciences, \\ Sevagram, Wardha, Maharashtra, India
}

Correspondence should be addressed to: Shakuntala Chhabra ; chhabra_s@rediffmail.com

Received date: 12 March 2014; Accepted date: 31 July 2014; published date: 7 September 2016

Academic Editor: Neelam Aggarwal

Copyright (@ 2016. Shakuntala Chhabra, Arpita Jaiswal and Anupriya Singh. Distributed under Creative Commons CC-BY 4.0

\begin{abstract}
Hypertensive disorders of pregnancy continue to be unresolved dilemma even today, with dangerous repercussions on maternal, perinatal morbidity mortality. The prediction becomes imperative for prevention. During pregnancy, normally there is increase in blood volume, heart rate, stroke volume, and cardiac output, however, there may be variations and their implications. The present study was done to know the predictive value of measurement of cardiac output in early pregnancy for knowing the occurrence of hypertensive disorders. The cardiac output (CO) was measured at $10 \pm 2$ weeks, $14 \pm 2$ weeks, $18 \pm 2$ weeks, $22 \pm 2$ weeks, $26 \pm 2$ weeks, $30 \pm 2$ weeks of pregnancy and 7 days post partum. Of 500 cases studied, in those with high cardiac output, $7.4 \%$ developed hypertensive disorders, of cases who had normal cardiac output , $0.5 \%$ developed hypertensive disorders and cases in whom cardiac output was less, no one developed hypertensive disorders. The $\mathrm{CO}$ at $10 \pm 2$ weeks had high positive and high correlation with $\mathrm{CO}$ at increasing gestation. Those with high $\mathrm{CO}$ at $10 \pm 2$ weeks had a risk of developing hypertensive disorders with significant co relation between high maternal $\mathrm{CO}$ and occurrence of hypertensive disorders.
\end{abstract}

Synopsis: Women with high cardiac output at $10 \pm 2$ weeks of pregnancy are at high risk of developing hypertensive disorders.

Keywords: Early Pregnancy, Cardiac Output, Prediction, Hypertensive Disorders of Pregnancy

Cite this Article as: Shakuntala Chhabra, Arpita Jaiswal and Anupriya Singh (2016), " Prediction of Hypertensive Disorders of Pregnancy by Measuring Cardiac Output in Early Pregnancy " Obstetrics \& Gynecology: An International Journal, Vol. 2016 (2016), Article ID 827403, DOI: 10.5171/2016.827403 


\section{Introduction}

Hypertensive disorders of pregnancy continue to be responsible for maternal, perinatal morbidity, mortality. Prevention of hypertensive disorders of pregnancy would be a very important contribution to the prevention of maternal perinatal mortality, but for prevention, prediction is essential, so the research continues. Predictive modality has to be feasible, cost effective, simple for use in all the mothers who really need it. Cardiac output increases by 30 to $50 \%$ during pregnancy [1-5]. In pregnancy, there is increased blood volume, heart rate (HR), stroke volume (SV), and cardiac output $(\mathrm{CO})^{[1-3]}$. It has been reported that maternal blood volume and cardiac output increase more in cases of hypertensive disorders of pregnancy ${ }^{[6-8]}$. So, it was decided to measure cardiac output in early pregnancy to know whether it is possible to predict hypertensive disorders.

Objectives of the present study were to know the predictive value of $\mathrm{CO}$ at $10 \pm 2$ weeks of pregnancy for $\mathrm{CO}$ in later weeks of pregnancy and relation with the occurrence of hypertensive disorder for knowing whether it is possible to predict hypertensive disorders by measuring $\mathrm{CO}$ in early pregnancy.

\section{Material Methods}

The present prospective study was carried out after taking approval of the ethics committee of the institute. The study subjects were pregnant women who had reported to the outpatient at early gestation, were willing, to follow; had birth at the place of study and gave consent for inclusion in study. During the study period, 7285 pregnant women had presented to outpatient. Out of which 568 women of early gestation $(<12$ weeks), were the study subjects after taking informed consent, with plans to follow and record the outcome of pregnancy. All women included in the study were primigravida, multigravida of 1840yrs with singleton pregnancy, however most were of 20-34 yrs with no known medical disorders, no obstetric problem at the time of entry to study, real strength of the study. CO was measured at $10 \pm 2$ weeks, 14 \pm 2 weeks, $18 \pm 2$ weeks, $22 \pm 2$ weeks, $26 \pm$ 2 weeks, $30 \pm 2$ weeks of pregnancy, and follow up was done till delivery and 7 days post partum. Challenge was taking women to the department of physiology for measuring CO.

Detailed history was taken, examination and investigations were done. Cardiac output was measured by thoracic electrical impedance plethysmography. Of the 568 women registered in the beginning of the study, 68 were lost to follow up, so 500 were the final study subjects.

\section{Results}

At $10 \pm 2$ weeks, gestation mean cardiac output was $5.77 \mathrm{~L} / \mathrm{min}$. Out of the total 500 women, 236 women had cardiac output between 5-5.49 L/min, 4 (1.69 \%) of them later developed hypertensive disorders 157 women had cardiac output between 5.5-5.99 $L / \mathrm{min}, 30(19.10 \%)$ of them later had hypertensive disorder significantly more (P value $<0.05$ ) (Table 1) and the rest 7 were lost to follow up. 
Table 1: Correlation between CO at $10 \pm 2$ Weeks and Effect on Mother

\begin{tabular}{|c|c|c|c|c|c|}
\hline \multirow{2}{*}{$\begin{array}{l}\text { CO In } \\
\mathrm{L} / \mathrm{min}\end{array}$} & \multirow{2}{*}{ TOTAL } & \multirow{2}{*}{$\begin{array}{l}\text { Effect On } \\
\text { Mother }\end{array}$} & \multirow{2}{*}{$\begin{array}{c}\text { Pregnancy } \\
\text { Disease }\end{array}$} & \multicolumn{2}{|c|}{ Distribution of women } \\
\hline & & & & No & $\%$ \\
\hline \multirow{4}{*}{$>5$} & \multirow{4}{*}{$\begin{array}{c}63 \\
(12.6 \%)\end{array}$} & No Disease & No Disease & 027 & 42.85 \\
\hline & & \multirow{2}{*}{ Disease } & Others & 036 & 57.14 \\
\hline & & & HD & 000 & 00.00 \\
\hline & & & Total & 063 & 100.0 \\
\hline \multirow{4}{*}{$5-5.49$} & \multirow{4}{*}{$\begin{array}{c}236 \\
(47.2 \%)\end{array}$} & No Disease & No Disease & 200 & 84.74 \\
\hline & & \multirow{2}{*}{ Disease } & Others & 032 & 13.55 \\
\hline & & & HD & 004 & 01.69 \\
\hline & & & Total & 236 & 100.0 \\
\hline \multirow{4}{*}{ 5.5-5.99 } & \multirow{4}{*}{$\begin{array}{c}157 \\
(31.4)\end{array}$} & No Disease & No Disease & 096 & 61.14 \\
\hline & & \multirow{2}{*}{ Disease } & Others & 031 & 19.73 \\
\hline & & & HD & 030 & 19.10 \\
\hline & & & Total & 157 & 100.0 \\
\hline \multirow{4}{*}{$6-6.49$} & \multirow{4}{*}{$\begin{array}{c}42 \\
(8.40)\end{array}$} & No Disease & No Disease & 031 & 73.80 \\
\hline & & \multirow{2}{*}{ Disease } & Others & 008 & 19.04 \\
\hline & & & HD & 003 & 07.14 \\
\hline & & & Total & 042 & 100.0 \\
\hline \multirow{4}{*}{$>6.5$} & \multirow{4}{*}{$\begin{array}{c}04 \\
(0.80)\end{array}$} & No Disease & No Disease & 000 & 00.00 \\
\hline & & \multirow{2}{*}{ Disease } & Others & 004 & 100.0 \\
\hline & & & HD & 000 & 00.00 \\
\hline & & & Total & 004 & 100.0 \\
\hline Total & 500 & & & 500 & 100.0 \\
\hline
\end{tabular}

HD=Hypertensive Disorder, CO = Cardiac Output

At $20 \pm 2$ weeks, gestation mean cardiac output was $6.14 \mathrm{~L} / \mathrm{min}$. Out of 500 women, 191 women had cardiac output between 6$6.5 \mathrm{~L} / \mathrm{min}, 3$ of them ( $1.57 \%$ ) later developed hypertensive disorders, 126 women had cardiac output above $6.5 \mathrm{~L} / \mathrm{min}$, 33 (26.19\%) later developed hypertensive disorders (significant difference $\mathrm{P}$ value $<0.05$ ) (Table 2). 
Table 2: Correlation between $\mathrm{CO}$ at $\mathbf{2 0} \pm 2$ Weeks and Effect on Mother

\begin{tabular}{|c|c|c|c|c|c|}
\hline \multirow{2}{*}{$\begin{array}{c}\text { CO In } \\
\mathrm{L} / \mathrm{min}\end{array}$} & \multirow{2}{*}{ TOTAL } & \multirow{2}{*}{$\begin{array}{l}\text { Effect On } \\
\text { Mother }\end{array}$} & \multirow{2}{*}{$\begin{array}{c}\text { Pregnancy } \\
\text { Disease }\end{array}$} & \multicolumn{2}{|c|}{ Distribution of women } \\
\hline & & & & No & $\%$ \\
\hline \multirow{4}{*}{ 5-5.49 } & \multirow{4}{*}{$\begin{array}{l}10 \\
(2)\end{array}$} & No Disease & No Disease & 02 & 20.00 \\
\hline & & \multirow{2}{*}{ Disease } & Others & 08 & 80.00 \\
\hline & & & HD & 00 & 00.00 \\
\hline & & & Total & 10 & 100.0 \\
\hline \multirow{4}{*}{ 5.5-5.99 } & \multirow{4}{*}{$\begin{array}{c}173 \\
(34.60)\end{array}$} & No Disease & No Disease & 89 & 51.45 \\
\hline & & \multirow{2}{*}{ Disease } & Others & 83 & 47.98 \\
\hline & & & HD & 01 & 00.57 \\
\hline & & & Total & 173 & 100.0 \\
\hline \multirow{4}{*}{ 6-6.49 } & \multirow{4}{*}{$\begin{array}{c}191 \\
(38.20)\end{array}$} & No Disease & No Disease & 185 & 96.86 \\
\hline & & \multirow{2}{*}{ Disease } & Others & 03 & 01.57 \\
\hline & & & HD & 03 & 01.57 \\
\hline & & & Total & 191 & 100.0 \\
\hline \multirow{4}{*}{$>6.5$} & \multirow{4}{*}{$\begin{array}{c}126 \\
(25.20)\end{array}$} & No Disease & No Disease & 78 & 61.90 \\
\hline & & \multirow{2}{*}{ Disease } & Others & 15 & 11.90 \\
\hline & & & $\mathrm{HD}$ & 33 & 26.19 \\
\hline & & & Total & 126 & 100.0 \\
\hline & 500 & & & 500 & 100.0 \\
\hline
\end{tabular}

HD=Hypertensive Disorder, Co = Cardiac Output

At $30 \pm 2$ weeks, the mean cardiac output was $6.36 \mathrm{~L} / \mathrm{min}$. Of 500 women 216 had cardiac output more than $6.5 \mathrm{~L} / \mathrm{min}, 36(16.66 \%)$ developed hypertensive disorder (significant difference from those with less CO (P value $<0.05$ ) (Table 3). 
Table 3: $\mathrm{CO}$ at $30 \pm 2$ Weeks and Effect on Mother

\begin{tabular}{|c|c|c|c|c|c|}
\hline \multirow{2}{*}{$\begin{array}{l}\text { CO In } \\
\mathrm{L} / \mathrm{min}\end{array}$} & \multirow{2}{*}{ TOTAL } & \multirow{2}{*}{$\begin{array}{c}\text { Effect On } \\
\text { Mother }\end{array}$} & \multirow{2}{*}{$\begin{array}{c}\text { Pregnancy } \\
\text { Disease }\end{array}$} & \multicolumn{2}{|c|}{ Distribution of women } \\
\hline & & & & No & $\%$ \\
\hline \multirow{4}{*}{$5-5.49$} & \multirow{4}{*}{$\begin{array}{c}05 \\
(1.00)\end{array}$} & No Disease & No Disease & 00 & 00.00 \\
\hline & & \multirow{2}{*}{ Disease } & Others & 05 & 100.0 \\
\hline & & & HD & 00 & 00.00 \\
\hline & & & Total & 05 & 100.0 \\
\hline \multirow{4}{*}{ 5.5-5.99 } & \multirow{4}{*}{$\begin{array}{c}147 \\
(29.4)\end{array}$} & No Disease & No Disease & 70 & 47.60 \\
\hline & & \multirow{2}{*}{ Disease } & Others & 76 & 51.69 \\
\hline & & & HD & 01 & 00.68 \\
\hline & & & Total & 147 & 100.0 \\
\hline \multirow{4}{*}{$6-6.49$} & \multirow{4}{*}{$\begin{array}{c}132 \\
(26.4)\end{array}$} & No Disease & No Disease & 120 & 90.90 \\
\hline & & \multirow{2}{*}{ Disease } & Others & 12 & 09.10 \\
\hline & & & HD & 00 & 00.00 \\
\hline & & & Total & 132 & 100.0 \\
\hline \multirow{5}{*}{$>6.5$} & \multirow{4}{*}{$\begin{array}{c}216 \\
(43.2)\end{array}$} & No Disease & No Disease & 164 & 75.92 \\
\hline & & \multirow{2}{*}{ Disease } & Others & 16 & 07.42 \\
\hline & & & HD & 36 & 16.66 \\
\hline & & & Total & 216 & 100.0 \\
\hline & 500 & & & 500 & 100.0 \\
\hline
\end{tabular}

Figures in bracket indicate \%

\section{HD=Hypertensive Disorder, CO = Cardiac Output}

Cardiac output was not affected by residence and age at any gestation ( $\mathrm{P}$ value at all gestations was >0.05.), no significant difference ( $\mathrm{P}$ value $>0.05$ ) in mean $\mathrm{CO}$ at different gestations in relation to parity and also no significant difference was seen with age ,parity and mean $\mathrm{CO}$ at different gestations as $\mathrm{P}$ value at different gestations was $>0.05$.

There was no significant difference in mean $\mathrm{CO}$ at different gestations in relation to BMI ( $\mathrm{P}$ value $>0.05$ ). Also, there was no significant difference $(\mathrm{P}$ value $>0.05$ ) in mean $\mathrm{CO}$ at different gestations in relation to age, BMI.
No significant difference ( $\mathrm{P}$ value $>0.05$ ) was seen in mean $\mathrm{CO}$ at different gestations in relation to age, weight.

Overall, the $\mathrm{CO}$ at $10 \pm 2$ weeks had a high degree of correlation with cardiac output at increasing gestation $(\mathrm{P}=<0.001)$, and the predicted cardiac output with increasing gestation could be estimated using analysis of variance of cardiac output at $10 \pm 2$ weeks. Overall, women who had high cardiac output in early pregnancy were more prone to develop hypertensive disorders. 


\section{Discussion}

As of present times, the ultimate primary prevention of hypertensive disorders of pregnancy is avoidance of pregnancy. Secondary prevention of the disease requires knowledge of the patho-physiological mechanism and modality of prevention. If the disease cannot be prevented, there should be available, usable techniques for the detection of disorder at early stage and after the detection, intervention of the disease process is essential [9-10]. But for the prevention of the disease, its severity and death due to the disease, prediction is necessary, which has limitations as of now, so the research continues. Cunningham reports that the cardio- vascular hemodynamics of the women with severe preeclampsia are characterized by normal or reduced $\mathrm{CO}$ and elevated vascular resistance [6]. However, Easterling had earlier conducted a study designed to test the hypothesis that preeclampsia is associated with high cardiac output, where in researchers measured the CO using Doppler during pregnancy and postpartum in women with preeclampsia and concluded that $\mathrm{CO}$ was elevated throughout pregnancy in women who later developed preeclampsia [11]. At 6 weeks postpartum, the cardiac output was elevated though the hypertension was resolved $(p=001)$ and peripheral resistance remained lower than in the normotensive subjects $(\mathrm{p}=001)$.

In a longitudinal study of 400 primigravidae studied with doppler echocardiography by Bosio et al, the researchers reported that the gestational hypertension developed in 24 $(6.34 \%)$ women and preeclampsia in 20 (5.29\%) women out of the 378 women who completed the pregnancy [7]. Women with preeclampsia had significantly elevated CO before clinical diagnosis of hypertensive compared to normotensive controls, but total peripheral resistance was not significantly different during this latent phase. Study findings supported the hyperdynamic disease model with a subsequent crossover to low cardiac output state.
In the study by De Paco et al [12,] CO was significantly higher in the preeclampsia and PIH cases, and in these cases alterations in maternal CO predated the clinical onset of the disorders by several months. Maternal $\mathrm{CO}$ in the first trimester was found to be increased in women who developed preeclampsia later. Most of the research and studies about the relationship with cardiac output have been in patients with hypertensive disorders, and the studies on normal pregnancies for prediction are scarce. When prediction is possible, then only an intervention can be thought of. Easterling conducted an interventional study to determine if the assessment of maternal hemodynamics could predict women at risk for the development of preeclampsia, whether treatment directed at hemodynamic abnormalities before the onset of hypertension could prevent hypertensive disorders of pregnancy [13]. Nulliparous and diabetic subjects at risk were treated with $100 \mathrm{mg}$ of atenolol or placebo. Researchers concluded that women at risk for hypertensive disorders of pregnancy can be identified by the measurement of $\mathrm{CO}$ in the second trimester, and treatment with atenolol decreased the occurrence of hypertensive disorders. Carr did a study to evaluate whether women with risk for disorders had a hyperdynamic circulation, and concluded that women with clinical risk factors had hyperdynamic circulation in the early second trimester compared with women at low risk ${ }^{[8]}$. These women also had evidence of increased endothelial activation as assessed by measuring plasma vascular cell adhesion molecule.

Tihtonen conducted a study assessing haemodynamic parameters by whole-body impedance cardiography noninvasively with the purpose of determining how hypertensive disorders of pregnancy modify maternal haemodynamics [14]. In women with hypertensive disorders of pregnancy, there was higher systemic vascular resistance index (SVRI), mean arterial pressure (MAP) and lower stroke index (SI) and cardiac index (CI), thus the baseline haemodynamics was 
significantly different in women with hypertensive disorders from healthy women.

In the present study, out of total 500 women studied, 37 (7.4\%) developed hypertensive disorders. Their mean $\mathrm{CO}$ at $10 \pm 2$ weeks gestation was $5.77 \mathrm{~L} / \mathrm{min}$ which increased to $6.94 \mathrm{~L} / \mathrm{min}$ at $30 \pm 2$ weeks. Women who had low cardiac output in early pregnancy had less risk of developing hypertensive disorders, while women who had high $\mathrm{CO}$ in the early pregnancy were at increased risk of developing hypertensive disorders later; significant relation was seen between high maternal $\mathrm{CO}$ and hypertensive disorders.

The present study of prediction of hypertensive disorders by estimating $\mathrm{CO}$ from early pregnancy reveals that, no significant difference was seen with age, parity, height, weight and BMI and mean $\mathrm{CO}$ at different gestations.

In the present study of prediction of hypertension disorders by estimating the $\mathrm{CO}$ from early pregnancy reveals that, the $\mathrm{CO}$ at $10 \pm 2$ weeks has positive and high degree of correlation with hypertensive disorders of pregnancy $\quad(\mathrm{P}=<0.001)$, and CO was maximum at $22 \pm 2$ weeks and $\mathrm{CO}$ at $10 \pm 2$ weeks was predictor of $\mathrm{CO}$ at $30 \pm 2$ weeks and a significant relation was found between high maternal $\mathrm{CO}$ and hypertensive disorders.

An attempt has been made in the present study for the prediction of hypertensive disorders by estimating $\mathrm{CO}$ from early pregnancy. Conclusions drawn from the study also include no significant relation between $\mathrm{CO}$ at different gestation with age, parity, height, weight and BMI, and women who had high cardiac output in early pregnancy were more prone to develop hypertensive disorders.

\section{Acknowledgement}

Authors are grateful to the women who agreed to participate and to everyone in the Department of physiology, especially the head of the department for the help.

\section{Disclosure Policy}

Competing interest none.

\section{References}

1. Pipkin FB, Chamberlain G, Steer PJ.Maternal physiology in pregnancy, Turnbulls Obstetrics, third edition Churchil Livingstone, Sydney, Toronto 2001; 71-91.

2. O'Toole, M.L. Physiologic aspects of exercise in pregnancy. Clin Obstet Gynecol. 2003., 46(2):379-389.

3. Foley MR, Maternal cardiovascular and hemodynamic adaptation to pregnancy, Uptodate patient information. 2007; 15,3.

4. Chapman AB, Abraham WT, Zamudio S Coffin C, Merouani A, Young D, Johnson A, Osorio F, Goldberg C, Moore LG, Dahms T, Schrier RW. Temporal relationships between hormonal and hemodynamic changes in early human pregnancy. Kidney Int. 1998; 54; 2056-2063.

5. David P, Maternal cardiac disease, Developing Anaesthesia.org 2007.

6. Cunningham F, Gant N, Gilstrap L, Hauth J., Wenstrom $K$. Hypertensive disorder in pregnancy. In Williams Obstetrics 21th ed. The McGraw-Hill Companies, Singapore, 2003. 567-617.

7. Bosio PM, McKenna PJ, Conroy R, O'Herlihy C. Maternal central hemodynamics in hypertensive disorders of pregnancy. Obstet Gynecol. 1999; 94:978-984.

8. Carr DB, McDonald GB, Brateng D, Desai $M$, Thach T, Easterling TR. The relationship between hemodynamics and inflammatory activation in women at risk for preeclampsia. Obstetrics \& Gynecology 2001; 98:11091116.

9. Barker, D. J. "The developmental origins of well-being." Philos Trans R Soc Lond B Biol Sci 2004: 359(1449): 1359-1366. 
10. Dekker, G. and Sibai B. "Primary, secondary, and tertiary prevention of preeclampsia." Lancet . 2001: 357(9251): 209215.

11. Easterling T Carr DB, McDonald GB, Brateng D, Desai $M$, Thach $T$, Easterling TR.The relationship, Benedetti T, Schmucker B, Millard S. Maternal hemodynamics in normal and preeclamptic pregnancies. A longitudinal study.Obstet Gynecol. 1990;76: 1061-9.

12. De Paco C, Kametas N, Rencoret G, Strobl I, Nicolaides KH. Maternal cardiac output between 11 and 13 weeks of gestation in the prediction of preeclampsia and small for gestational age. Doi: 10.1097/01.AOG.0000298622.22494.0c. 2008;111 (2 Pt 1): 292-300

13. Easterling T, Brateng D, Schmucker B, Brown Z, Millard S. Prevention of preeclampsia: A randomized trial of atenolol in hyperdynamic patients before onset of hypertension. Obstet Gynecol. 1999; 93:72533.

14. TihtonenKati ,Maternalhaemodynamics in hypertensive and normotensive pregnancy, ActaUniversitatis Tamperensis; 2006; 1189. 